\title{
USO DA REGIÃO VENTROGLÚTEA COMO ALTERNATIVA PARA ADMINISTRAÇÃO DE IMUNOBIOLÓGICOS: UMA REVISÃO BIBLIOGRÁFICA
}

\section{USE OF ALTERNATIVE VENTROGLUTEAL SITE IMMUNOBIOLOGICAL ADMINISTRATION: A LITERATURE REVIEW}

TAVARES, V.R.; SOUZA NETO, M.A.; TRINDADE, N.R; M.A.; SILVA, G. A.

Viviane Rodrigues Tavares; Coordenadora e professora do curso de Enfermagem - FACERES. Mestre em Enfermagem-UFG. vianevivi@hotamil.com; coordenaçãoenf@faceres.edu.br Fones: 8582-0266; 81602241; 3233-7889. Rua 258 no 15. Setor Coimbra. Goiânia. Goiás. Cep. 74.535.470.

Menandes Alves de Souza Neto Coordenador e professor do curso de farmácia-FACERES. Mestre em Biologia Celular e Molecular UFG. menandesneto@gmail.com; coordenacaofarm@faceres.edu.br. Fones: (6282664292; (62)33072365. Rua João Alves Reis Q03 lote 22. Setor Bouganville. Ceres. Goiás. Cep: 76.300.000

Nediane Rosa Trindade Professora supervisora de Estágio supervisionado em enfermagem -FACERES.Fones: (62) 81722430 (62)33072365. Rua João Alves Reis Q03 lote 22. Setor Bouganville. Ceres. Goiás. Cep: 76.300.000

Gilmar Aires da Silva. Professor do curso de Farmácia - FACERES. Fones: 84480243.Avenida Brasil, s/n, Qd. 13. Setor Morada Verde. Ceres. Goiás. Cep. 76.3000 .000 .

\section{RESUMO}

A administração de imunobiológicos é uma atividade que deve ser desempenhada por profissionais com domínio de habilidades e conhecimento. Para escolha do local de aplicação das mais diversas vacinas, critérios como menor reatogenicidade e melhor imunogenicidade devem ser considerados. Este estudo teve como objetivo investigar as evidências disponíveis na literatura sobre a administração de imunobiológicos na região ventroglútea, ressaltando as vantagens e desvantagens desta via. Tratou-se de uma pesquisa descritiva de natureza bibliográfica realizada por meio das bases de dados. Foram pesquisados artigos que estudaram a utilização da região ventroglútea como área de escolha para administração de injetáveis. O estudo demonstrou apesar de ser uma região segura para administração de vacinas, ainda não é bem aceita pelos profissionais de saúde.

Palavras-chaves: vacina, ventroglúeta 


\section{ABSTRACT}

The administration of immunobiological is an activity that should be performed by professionals with domain knowledge and skills. To choose the site of application of various vaccines, criteria such as low reactogenicity and immunogenicity best should be considered. This study aimed to investigate the evidence available in the literature on the management of the immunobiological ventrogluteal site, highlighting the advantages and disadvantages of this route. This was a descriptive nature of bibliographic through databases. We searched articles that studied the use of ventrogluteal site as an area of choice for intravenous administration. The study demonstrated despite being a safe region for vaccine administration, yet not well accepted by health professionals.

KEYWORDS: vaccine, ventrogluteal

\section{INTRODUÇÃO}

A vacinação é um dos instrumentos de política de Saúde Pública com o intuito de reduzir ou eliminar o número de enfermidades com altos índices de mortalidade e morbidade. Historicamente, o primeiro relato quanto à técnica de imunização foi feita por Edward Jenner, em 1798, ao observar que ordenhadores de vacas infectadas com cowpox (varíola bovina), não adquiriam varíola ao terem contato com doentes. Entretanto, a relação causa-efeito entre a presença de microrganismos patogênicos e doenças apenas foi estabelecida por Louis Pasteur e Robert Koch, aproximadamente em 1870 (MARCHIOTNATTI; DIAS; SILVA, 2003; FEIJO; SAFADI, 2006).

Estudos apontam os efeitos das imunizações, assim como o significado da erradicação de doenças em nível mundial. Inicialmente, as ações de imunização possuíam atuação isolada através de programas nacionais para doenças especificas como poliomielite, sarampo, tuberculose, difteria, tétano e coqueluche, porém, como forma de redirecionar a atuação governamental, a Organização Mundial Saúde (OMS) cria o Programa Ampliado de Imunização (PAl) definindo as vacinas obrigatórias e permitindo a implementação de medidas complementares na ampliação das coberturas vacinais (WHO, 2004).

No Brasil, o Ministério da Saúde (MS) implantou em 1971, o Programa Nacional de Imunização (PNI), que é considerado um dos mais completos dentre os países em desenvolvimento. Com a Política de oferecer de forma universal o acesso à vacinação à população alvo - crianças, adolescentes, idosos e índios, este programa foi capaz de erradicar em 1973 e em 1989, a varíola e a poliomielite respectivamente. Desenvolve ainda, ações planejadas e sistematizadas no controle do sarampo, o tétano neonatal, as formas graves da tuberculose, a difteria, o tétano acidental e a coqueluche. Programa medidas para o controle da caxumba, rubéola e da síndrome da rubéola congênita, da hepatite B, das infecções invasivas pelo Haemophilus influenzae tipo b, da influenza e também das infecções pneumocócicas e suas complicações nos idosos. Recentemente, a vacina oral contra o rotavírus foi incorporada ao calendário vacinal de crianças menores de um ano (FEIJO; SAFADI, 2006).

As vacinas são imunobiológicos que contém um ou mais agentes imunizantes (vacina isolada ou combinada) sob diversas formas: bactérias ou vírus vivos atenuados, vírus inativados, bactérias mortas e componentes de agentes infecciosos purificados e/ou modificados quimicamente ou 
geneticamente (BRASIL, 2001). A administração destes pode ser por via oral, intramuscular, subcutânea, intradérmica ou percutânea, sendo que cada uma destas vias possuem particularidades e cuidados a serem seguidos (MANUAL DE IMUNIZAÇÃO, 2009).

$\mathrm{Na}$ administração de vacinas intramusculares é importante levar em consideração alguns fatores para a seleção do local apropriado, tais como massa muscular, idade, estado da pele, inervação e vascularização da área dentre outros. Trata-se de uma via adequada para a injeção de substâncias que necessitam de uma absorção rápida (JUNQUEIRA; SOUZA, 2004). Os locais mais utilizados para a aplicação de imunobiológicos intramusculares são os músculos vastolateral da coxa, o dorso glúteo, e deltóide (BRASIL, 2001). Os manuais e protocolos que estabelecem os aspectos gerais e padronizam as técnicas para a administração de vacinas na rede de serviços de saúde pelo $\mathrm{PNI}$ ainda não incluíram entre os locais de escolha a região ventro-glútea. Apesar de ter sido introduzida na prática em 1954 pelo anatomista suíço Von E. Hoschstetter refere-se a uma região pouco conhecida e utilizada pelos profissionais de saúde (JUNQUEIRA; SOUZA, 2004; GODOY et al, 2004).

No entanto, estudos afirmam que esta área é indicada para qualquer faixa etária e a mais segura e adequada para a aplicação de injetáveis, por possuir uma vasta musculatura, com espessura aproximada de $4 \mathrm{~cm}$ na zona central do músculo mínimo e médio, ser livre de estruturas importantes e possuir pequenos nervos, além da concavidade do osso ilíaco impedir deslocamento da substância para o nervo ciático (JUNQUEIRA; SOUZA, 2004; COOK; MURTAGH, 2006). Outros estudos têm demonstrado que as vacinas feitas na região ventroglútea apresentam a mesma imunogenicidade observada em outras áreas intramusculares (COOK; MURTAGH, 2003; COOK; MURTAGH, 2006; JUNQUEIRA et al., 2010).

Revisões bibliográficas quanto à administração de vacinas na região ventroglútea são raras na literatura, além disso, essa região não é a de escolha nas salas de vacinas do país, embora estudos tenham sido desenvolvidos e sempre ratificando a segurança e a eficácia da imunização nessa região. Diante disso nos propusemos a realizar este estudo, no intuito de despertar a consciência dos profissionais responsáveis pela administração de injetáveis sobre a segurança e eficácia da região ventroglútea, e assim transformar a prática, através de evidências científicas.

\section{OBJETIVO}

Investigar as evidências disponíveis na literatura sobre a administração de imunobiológicos na região ventroglútea.

\section{METODOLOGIA}

Trata-se de uma pesquisa descritiva de natureza bibliográfica realizada por meio das bases de dados LILACS, MEDLINE e Biblioteca Cochrane. Foram pesquisados artigos com idiomas inglês, português, espanhol, entre o perído de 1997 a 2011, que estudaram a utilização da região ventroglútea como área de escolha para administração de injetáveis. Os descritores ventrogluteal e vaccines foram usados isoladamente ou em combinação na pesquisa.

Após analise criteriosas das 23 referências encontradas, e manuais foram inclusos oito artigos em nosso estudo, dentre eles haviam: um 
encontrado no banco de dados LILACS, nove no MEDLINE e um no Cochrane, sendo que dois artigos eram idênticos no MEDLINE e Cochrane e deste último seis foram exclusos por não se adequarem a nossos critérios de seleção e não abordarem o nosso objeto de estudo.

A análise dos dados foi realizada por etapas, a saber: inicialmente, foi feita a leitura exploratória, seguido da separação do material que realmente seria utilizado, para então processarmos a leitura analítica e por fim, a interpretativa; posteriormente, fizemos a tomada de apontamentos, anotando as idéias principais e os dados importantes em relação ao objetivo da pesquisa.

\section{RESULTADOS E DISCUSSÕES}

Os dados disponíveis sugerem que a administração intramuscular de imunobiológicos deve ser realizada na região vasto-lateral da coxa em crianças. Entretanto estudos sugerem que a região ventroglútea é a mais adequada para todas as faixas etárias (SCHECHTER et al., 2007; COOK, MURTAGH, 2006).

Schechter et al (2007) identificaram a eficácia de intervenções disponíveis no alivio da dor durante a administração de imunobiológicos, e concluíram que a região ventroglútea pode ser uma alternativa, associadados principalmente a técnica de distração da criança durante a realização do procedimento, o uso de sacarose, controle emocional dos pais, pressão do local pós-administração, tamanho da agulha, e o local de preparação da vacina pode contribuir para a redução da dor.

Para Cook e Murtagh (2006) a região ventroglútea é a mais indicada para administração de medicamentos intramusculares devido à segurança que essa via fornece. Quando comparada com a administração de vacinas nas regiões recomendadas para a vacinação pediátrica (deltóide e antero lateral), a região ventroglútea tem menor reatogenicidade e semelhante imunogenicidade. Esses estudiosos dedicaram-se na realização de pesquisas que confirmassem a segurança, a aceitabilidade dos familiares, a menor reatogenicidade e a imunogenicidade de vacinas administradas nessa região quando comparada com outras áreas.

Em 2002, Cook e Murtagh em um estudo randomizado, realizado com 200 lactentes saudáveis no início do esquema vacinal, compararam a resposta imunológica da vacina contra hepatite $B$ administrada por via intramuscular na região vastolateral da coxa e ventroglútea. Os lactentes foram vacinados com a vacina contra hepatite $B$ seguindo o esquema: 0 meses, 1 mês, 6 meses, e coletado sangue venoso, 4-6 semanas após a última dose de vacina, para a determinação quantitativa de anticorpos anti - HBs (anti-HBs). Verificaram que nas regiões ventroglútea e antero lateral da coxa em lactentes é imunologicamente semelhante quando comparadas para a vacina contra hepatite $\mathrm{B}$.

Em 2003 os mesmos autores avaliaram a reatogenicidade da vacina tríplice bacteriana quando administrada nas regiões ventroglútea e antero lateral da coxa e observaram que reações adversas eram menos freqüentes na primeira.

Mais recentemente, na comparação da vacinação contra hepatite $B$ entre as regiões ventroglútea e antero lateral da coxa em lactentes verificaram que o resultado foi imunologicamente semelhante, como demonstra estudo 
randomizado realizado por Junqueira et al., 2010, com 580 recém-nascido que receberam o esquema vacinal na região antero lateral da coxa ou ventroglútea.

Greenway et al (2004), apresentam uma tentativa de sensibilização da população para a utilização da região ventroglútea para administração de injetáveis intramusculares, mudando assim a prática quotidiana, através de descrições das principais razões para o uso deste local. Analisa, ainda, as vantagens e desvantagens da utilização da região ventroglútea para administração de injetáveis quando comparada à região dorsoglútea, que embora seja ineficaz, inapropriada e potencialmente perigosa, é a região de escolha pelas enfermeiras para a administração de medicamentos por via intramuscular. Este estudo reafirma que a região ventroglútea possui uma menor quantidade de inervações e vasos sanguíneos, minimizando, portanto uma série de complicações inerentes a lesões em nervos e vasos importantes. Além disso, afirma que a região ainda é pouco aceita devido escassez de profissionais treinados e aptos para realizarem a técnica.

Godoy et al (2004) desenvolveram um estudo entre profissionais de enfermagem de um hospital escola do interior paulista, a equipe responsável pela administração de medicamento e que, por se tratar de uma intervenção em saúde deve ser feita por pessoas que dominem conhecimentos sobre os aspectos fundamentais que permeiam a técnica. Identificaram que as regiões de escolha por esses profissionais para administração de medicamentos intramuscular são as dorsoglútea e deltóidea, evidenciaram, nestes profissionais, dificuldade em descrever o método usado para delimitar as regiões para aplicação de medicamentos intramuscular e pouco conhecimento na identificação de complicações e contra-indicações. Ainda, observaram que a região ventroglútea ainda é pouco utilizada, confirmando a baixa adesão a esse método e validando a necessidade de atualização desses profissionais, especialmente no que se refere à anatomia, e terminologia adequada utilizada para designar as regiões e os conhecimentos de complicações e contraindicações.

$\mathrm{Na}$ aplicação de injetáveis intramuscular, existe o risco de lesão do nervo ciático, principalmente em região de dorsoglúteo. Foram encontradas evidências de que as injúrias ao nervo ciático estão associadas à utilização da região dorsoglútea, com o consenso de que a região ventrogluteal é a mais adequada para a administração de injetáveis. Sugerindo que a escolha do local deve basear-se em boa avaliação clínica, utilizando os melhores dados disponíveis e avaliação individualizada do cliente, onde o enfermeiro deve ter um pleno domínio da anatomia da região e das estruturas (SMALL, 2004).

Artioli et al (2002), identificaram na literatura de enfermagem dos últimos 20 anos que a região ventroglutea é recomendada como o melhor local para injeções intramusculares, porém em seu estudo realizado com 167 enfermeiras italiana a região não esta sendo muito aceita pelos profissionais, que optam para a utilização da região dorsoglútea. Dentre os critérios encontrados no estudo estão a localização do local de aplicação ser de fácil acesso, grande massa muscular, menor sensibilidade à dor e ao pedido do paciente, sugerindo a escolha dos profissionais mais por costume do que por evidências científicas.

A região ventroglútea é apontada como local de escolha para administração de medicamentos em geral e não especificamente quanto à via de uso de vacinas (DONALDSON; GREEN, 2005). Porém, as pesquisas sobre 
as injeções intramusculares são limitadas, com a conclusão que estudos sobre diversos aspectos do procedimento precisam ser elaborados, a fim de prestarem apoio às orientações clínicas.

\section{CONSIDERAÇÕES FINAIS}

Embora a região ventroglútea tenha sido identificada há várias décadas como local seguro para aplicação de injetáveis e, mais recentemente, vacinas, ainda não é aceita por aqueles que atuam na área da saúde, e essa baixa adesão dos profissionais na escolha do local para aplicação de injetáveis, é justificada pela falta de incentivos e treinamento da equipe.

Diante dos dados apresentados verifica-se que poucos estudos são realizados acerca da região ventroglútea, e quando associamos essa área a imunizações obtém-se um contingente ainda menor, confirmando que a não adesão por parte dos protocolos ministeriais está associada à escassez de evidências científicas quanto à segurança e as vantagens dessa via.

Ainda que haja poucos estudos a respeito dessa temática, estes afirmam a aceitação, segurança e as vantagens dessa região e a apontam como a mais adequada para a administração de injetáveis em geral, e que oferecem a mesma eficácia imunogênica e menores reações adversas, principalmente a dor local.

Com este estudo fica evidente a necessidade de mais pesquisas a cerca do assunto e que estas estejam disponíveis aos profissionais da área, além disso, é imprescindível educação permanente e treinamento da equipe.

\section{REFERÊNCIAS}

ARTIOLI G; FINOTTO S; CHIESI I; BIGI E. Criteria used by nurses in choosing the site for intramuscular injections: custom or scientific evidence? Prof Inferm; v. 55, n.4, p. 218-223, 2002.

BRASIL. Ministério da Saúde. Fundação Nacional de Saúde (FUNASA). Manual de Normas de Vacinação. 3.ed. Brasília; 2001, 72p.

COOK IF; MURTAGH J. Ventrogluteal area suitable site for intramuscular vaccination of infants and toddlers. Vaccine; v. 24, n.13, p.2403-2408, 2006.

Comparative reactogenicity and parental acceptability of pertussis vaccines administered into the ventrogluteal area and anterolateral thigh in children aged 2, 4, 6 and 18 months. Vaccine; v. 21, n. 23, p.33303334, 2003.

. Comparative immunogenicity of hepatitis $B$ vaccine administered into the ventrogluteal area and anterolateral thigh in infants. $\mathbf{J}$ Paediatr Child Health; v. 38, n.4, p. 393-396, 2002.

DONALDSON, C.; GREEN, J. Using the ventrogluteal site for intramuscular injections. Nurs. Times. v. 101(16), p. 19-25, 2005 
FEIJO, R.B.; SAFADI, M.A.P. Imunizações: três séculos de uma história de sucessos e constantes desafios. J. Pediatr., Rio de Janeiro, v.82, n.3, suppl, p.s1-s3, jul. de 2006.2 Disponível em: http://www.scielo.br/pdf/jped/v82n3s0/v82n3sa01.pdf. Acesso em: 29/10/2007.

GILIO, A.E. (coordenador). MANUAL DE IMUNIZAÇÃO: Centro de Imunização Hospital Israelita Albert Einstein. 3. ed. São Paulo: Office Editora, 2009.

GODOY, S; NOGUEIRA, MS; MENDES, IA. Intramuscular drug administration: analysis of knowledge among nursing professionals. Rev EsC Enferm USP; v.38, n.2, p.135-142, Jun. de 2004.

GREENWAY, K. Using the ventrogluteal site for intramuscular injection. Nurs Stand; v.18, n.25, p.39-42, 2004.

JUNQUEIRA, A.L.N.; SOUZA, ACS. Manual consultivo para profissionais de estabelecimento farmacêutico: Injetáveis com segurança. 4ํe․ Goiânia, 2004.

JUNQUEIRA, A.L.; et al. Safety and immunogenicity of hepatitis $B$ vaccine administered into ventrogluteal vs. anterolateral thigh sites in infants: a randomised controlled trial. Int. J. Nurs. Stud. n. 47(9), p. 1074-1079, 2010.

SCHECHTER NL; et al. Pain reduction during pediatric immunizations: evidence-based review and recommendations. Pediatrics. n. 119, v. 5, p. 1184-1198, 2007.

SMALL SP. Preventing sciatic nerve injury from intramuscular injections: literature review. J Adv Nurs; n. 47, v. 3, p. 287-296, 2004.

WHO. World Health Organization 2004. Immunization, Vaccines and Biologicals Department. Genebra, 2004. 